\title{
A DISCIPLINA DE LIBRAS NO CONTEXTO DE FORMAÇÃO ACADÊMICA EM FONOAUDIOLOGIA
}

\section{Libras discipline in speech language therapy academic context}

\author{
Ana Cristina Guarinello (1), Ana Paula Berberian (2), Daline Backes Eyng ${ }^{(3)}$, \\ Priscila Soares Vidal Festa ${ }^{(4)}$, Jair Mendes Marques ${ }^{(5)}$, Kyrlian Bartira Bortolozzi ${ }^{(6)}$
}

\begin{abstract}
RESUMO
Objetivo: analisar a inserção da disciplina de Libras em cursos nacionais de graduação em Fonoaudiologia, enfocando carga horária, período em que é ofertada, a natureza/estrutura da mesma; bem como, a avaliação de graduandos quanto à contribuição de tal disciplina na sua formação acadêmica e nas relações estabelecidas com sujeitos surdos. Método: foi aplicado um questionário a 240 acadêmicos de sete cursos de graduação em Fonoaudiologia, ofertados em Instituições de Ensino nacionais. Para tanto, adotou-se como critério de inclusão, acadêmicos que já tivessem cumprido a carga horária total da disciplina de Libras. O questionário foi respondido por escrito nas dependências dos cursos. Os resultados, analisados quantitativamente, foram organizados e apresentados em tabelas de frequências absolutas e relativas. Resultados: os achados demonstram que se por um lado dentre os acadêmicos predomina a visão de que a carga horária destinada à referida disciplina é insuficiente, por outro existe uma conscientização por parte dos mesmos quanto à importância e à necessidade da formação em Libras. Conclusão: a partir de tal estudo pode-se evidenciar a necessidade do aprofundamento de discussões no contexto fonoaudiológico acerca da formação acadêmica voltada a Libras, bem como a definição de critérios e parâmetros que garantam um ensino de qualidade em torno de tal conteúdo. Esse estudo aponta para a necessidade do implemento de pesquisas que ofereçam elementos para o avanço na formação acadêmica fonoaudiológica voltada ao referido conteúdo, bem como, contribuam para a avanço de práticas fonoaudiológicas bilíngues, clínicas e educacionais, dirigidas a sujeitos surdos.
\end{abstract}

DESCRITORES: Fonoaudiologia; Surdez; Linguagem; Leis; Educação

(1) Fonoaudióloga; Docente do Curso de Graduação em Fonoaudiologia e do Mestrado e Doutorado em Distúrbios da Comunicação da Universidade Tuiuti do Paraná - UTP, Curitiba, Paraná Brasil; Doutora em Estudos Linguísticos pela Universidade Federal do Paraná.

(2) Fonoaudióloga; Docente do Curso de Graduação em Fonoaudiologia e do Mestrado e Doutorado em Distúrbios da Comunicação da Universidade Tuiuti do Paraná - UTP, Curitiba, Paraná, Brasil; Doutora em História pela PUC/SP.

(3) Fonoaudióloga; Mestranda em Distúrbios da Comunicação pela Universidade Tuiuti do Paraná - UTP, Curitiba, Paraná, Brasil.

(4) Pedagoga; Mestranda em Distúrbios da Comunicação pela Universidade Tuiuti do Paraná - UTP, Curitiba, Paraná, Brasil.

(5) Estatístico; Docente do Programada de Mestrado e Doutorado em Distúrbios da Comunicação - UTP, Curitiba, Paraná, Brasil; Doutor em Ciências Geodésicas pela Universidade Federal do Paraná.

(6) Fonoaudióloga; Doutoranda em Distúrbios da Comunicação pela Universidade Tuiuti do Paraná - UTP, Curitiba, Paraná, Brasil.

Conflito de interesses: inexistente

\section{INTRODUÇÃO}

Pode-se acompanhar que, a partir da década de 1960, o reconhecimento e a adoção da língua de sinais, enquanto primeira língua dos $\operatorname{surdos}^{1} \mathrm{e}$ da língua nacional, como de uma segunda língua, passaram a ganhar força em diferentes países. Essa abordagem, primeiramente debatida e posta em prática nos Estados Unidos, passou a ser denominada como bilíngue e teve como um dos fundamentos originais a preservação da identidade e da cultura da comunidade surda ${ }^{2,3}$. A partir dessa perspectiva, entende-se que o surdo deve ser bilíngue $^{4}$ e, para tanto, deve adquirir como língua materna, a língua de sinais e como segunda língua, a língua oficial de seu país ${ }^{5,6}$. Isso porque, o modelo bilíngue ${ }^{7}$, gestado a partir de uma visão sócio antropológica da surdez, concebe a língua de sinais como a língua natural dos surdos ${ }^{8-10}$. 
Esses pressupostos ${ }^{11}$, além de subsidiarem uma Educação Bilíngue em diversos países, objetivam tornar acessível à criança duas línguas no contexto escolar ${ }^{12} \mathrm{e}$, no Brasil, estão alinhados aos princípios da Educação Inclusiva ${ }^{13}$, conforme pode ser apreendido nas Diretrizes Nacionais para Educação Especial na Educação Básica (Resolução CNE/ CEB no 2 , de 11 de Setembro de 2001) ${ }^{14}$. Formulado em 2001, tal documento destaca e reconhece a importância da língua de sinais no acesso do aluno surdo aos conteúdos curriculares.

Além de orientar abordagens educacionais, conforme acima descrito, ressalta-se que a proposta bilíngue, também, fundamenta uma perspectiva de atuação clínica fonoaudiológica que tem como prioridade a aquisição da segunda língua, tanto em sua modalidade oral, quanto escrita. Enfim, o modelo bilíngue pressupõe que o ensino da língua de sinais seja ministrado, especialmente, por um adulto surdo com proficiência, quer seja no contexto escolar, quer seja no contexto clínico, envolvendo nesse processo a família do surdo e que, articulada às ações desenvolvidas nesses contextos, a aquisição da oralidade e da escrita seja implementada a partir da intervenção clinica fonoaudiológica ${ }^{15}$.

Junto à oficialização da Libras, enquanto língua da comunidade surda brasileira, em abril de 2002, por meio da Lei $n^{\circ} 10.436^{16}$, pode-se acompanhar um avanço nas discussões e na sistematização de iniciativas voltadas à inclusão dos surdos no ensino regular ${ }^{17,18}$. Tal movimento resultou em reformulações no sistema educacional brasileiro as quais, por sua vez, criaram a necessidade de expandir o ensino da Libras a profissionais envolvidos diretamente com os processos de ensino-aprendizagem e com o desenvolvimento da linguagem vivenciados pelos surdos ${ }^{19}$. Nessa direção, a Lei $n^{\circ} 10.436^{16}$, no artigo $4^{\circ}$ dispõe que os sistemas educacionais federal, estadual e municipal brasileiros devem garantir a inclusão da Libras nos cursos de Educação Especial, de Fonoaudiologia e de Magistério, nos níveis médio e superior, como parte integrante dos Parâmetros Curriculares Nacionais ${ }^{20}$.

A proposta que integra os pressupostos básicos da Lei de Libras foi regulamentada por meio do Decreto $n^{\circ}$ 5.626, de 22 de dezembro de 200521, que em seu artigo $3^{\circ}$, especifica a inclusão da Libras, como disciplina curricular obrigatória nos cursos de formação de professores para o exercício do magistério, em nível médio e superior (aqui incluídas todas as licenciaturas, nas diferentes áreas do conhecimento, o curso de Pedagogia e o curso de Educação Especial), e nos cursos de Fonoaudiologia, de instituições de ensino públicas e privadas, no sistema federal de ensino e dos sistemas dos Estados, do Distrito Federal e dos Municípios. Esse mesmo artigo também decreta que a Libras constituir-se-á em disciplina curricular optativa nos demais cursos de educação superior e na educação profissional.

Se a Lei $n^{\circ} 10.436$ é apontada como um marco no reconhecimento da Libras enquanto a língua da comunidade surda, foi somente a partir da sua regulamentação, por meio do Decreto $n^{\circ} 5.626$, que houve um avanço na adoção da disciplina de Libras em cursos de graduação ${ }^{22}$. Esse avanço deve-se ao fato de que a partir da publicação do decreto ${ }^{21}$, as instituições de educação superior que oferecem cursos de Fonoaudiologia ou de formação de professores devem incluir a Libras como disciplina curricular obrigatória, nos seguintes prazos: até três anos em $20 \%$ dos cursos da instituição; em até cinco anos, em $60 \%$ dos cursos; em até sete anos, em $80 \%$ dos cursos; e em dez anos, em $100 \%$ dos cursos $^{21,23}$.

Apesar desse decreto ter estipulado um prazo para a efetivação da inclusão da disciplina nos cursos acima referidos, o mesmo não regulamenta, a exemplo da Lei $n^{\circ} 10.436$, aspectos relacionados ao período, à carga horária e à natureza da disciplina(teórico/prática).

Tendo em vista que os cursos de graduação em Fonoaudiologia iniciaram a inclusão da disciplina de Libras enquanto obrigatória, em seus currículos, a partir de 2005 e que tal processo encontra-se em desenvolvimento, ressalta-se a importância de estudos que ofereçam elementos que contribuam para a apreensão a análise de como tal disciplina vem sendo inserida na formação do fonoaudiólogo. Nessa direção, esse artigo tem por objetivo analisar a inserção da disciplina de Libras em cursos nacionais de graduação em Fonoaudiologia, enfocando carga horária, período em que é ofertada, a natureza/estrutura da mesma; bem como, a avaliação de graduandos quanto à contribuição de tal disciplina na sua formação acadêmica e nas relações estabelecidas com sujeitos surdos.

\section{MÉTODO}

Para a realização dessa pesquisa, foi aplicado um questionário a 240 acadêmicos de cursos de Graduação em Fonoaudiologia, ofertados por 7 instituições de ensino superior, duas situadas no Estado do Paraná, uma no Rio de Janeiro, uma em Minas Gerais, duas em São Paulo e uma em Santa Catarina.

O questionário, respondido individualmente e por escrito pelos acadêmicos nas dependências dos cursos de graduação, foi estruturado com questões relativas à disciplina de Libras enfocando 
carga horária, período em que é ofertada, estrutura/ natureza da mesma, sua contribuição na formação acadêmica e nas relações estabelecidas entre os acadêmicos e sujeitos surdos.

Ressalte-se que o nome das instituições foi mantido em sigilo e, portanto, a cada uma foi atribuído um número e a sigla do estado em que está alocada. Os acadêmicos foram esclarecidos quanto ao objetivo e à opção de participarem ou não da pesquisa. Adotou-se como critério de inclusão, acadêmicos que já houvessem cumprido a carga horária total da disciplina de Libras. Depois de esclarecido o objetivo da pesquisa, os participantes assinaram o termo de consentimento livre e esclarecido. Essa pesquisa foi aprovada pelo Comitê de
Ética da Universidade Tuiuti do Paraná, conforme o protocolo $n{ }^{\circ}$ 076/2006.

Os resultados, analisados quantitativamente, foram organizados e apresentados em tabelas de frequências absolutas e relativas. Ressalta-se a utilização do teste de diferença de proporções, ao nível de significância de 0,05 (5\%) para análise de alguns dos achados da pesquisa.

\section{RESULTADOS}

$\mathrm{Na}$ tabela 1 , constam dados relativos à distribuição do número de acadêmicos por Instituição, bem como à carga horária, ao período em que é ofertada e à estrutura curricular da disciplina de Libras.

Tabela 1 - Distribuição das Instituições, do número de acadêmicos, do período, da carga horária e da estrutura curricular da disciplina de Libras

\begin{tabular}{ccccc}
\hline \multirow{2}{*}{ Instituição } & \multicolumn{4}{c}{ DADOS GERAIS DAS INSTITUIÇÕES } \\
\cline { 2 - 5 } & $\mathbf{N}^{\circ}$ participantes & $\begin{array}{l}\text { Período de } \\
\text { graduação }\end{array}$ & Carga horária & $\begin{array}{c}\text { Estrutura } \\
\text { curricular }\end{array}$ \\
\hline 1-PR & 23 & $6^{\circ}, 7^{\circ}$ e $8^{\circ}$ & 108 & Teoria e prática \\
2-PR & 21 & $7^{\circ}$ & 72 & Teoria e prática \\
3-SC & 43 & $3^{\circ}, 5^{\circ}$ e $7^{\circ}$ & 30 & Teoria e prática \\
4-SP & 37 & $5^{\circ}$ e $7^{\circ}$ & 36 & Teoria e prática \\
5-SP & 31 & $5^{\circ}$ e $7^{\circ}$ & 30 & Teoria e prática \\
6-RJ & 25 & $3^{\circ}$ e $4^{\circ}$ & 30 & Teoria e prática \\
7-MG & 60 & $6^{\circ}, 7^{\circ}$ e $8^{\circ}$ & 120 & Teoria e prática \\
\hline
\end{tabular}

Na tabela 2 são apresentados os achados referentes à avaliação dos acadêmicos quanto à carga horária ofertada na disciplina de Libras.

Quando questionados a respeito da importância da disciplina de Libras no currículo do curso, 235 $(97,9 \%)$ responderam positivamente, enquanto
$5(2,1 \%)$ alunos afirmaram que a mesma não é importante para sua formação profissional. Através do Teste de Diferença de Proporções, ao nível de significância de 0,05 , verifica-se que a proporção dos acadêmicos que consideram importante a existência da disciplina é significante $(p=0,0000)$.

Tabela 2 - Avaliação dos acadêmicos quanto à carga horária destinada à disciplina

\begin{tabular}{ccccc}
\hline Instituição & Suficiente & Razoável & Insuficiente & Sem resposta \\
\hline 1-PR & $1(4,3 \%)$ & $9(39,1 \%)$ & $13(56,5 \%)$ & $-(0,0 \%)$ \\
2-PR & $2(9,5 \%)$ & $5(23,8 \%)$ & $14(66,7 \%)$ & $-(0,0 \%)$ \\
3-SC & $-(0,0 \%)$ & $8(18,6 \%)$ & $34(79,1 \%)$ & $1(2,3 \%)$ \\
$4-S P$ & $-(0,0 \%)$ & $10(27,0 \%)$ & $27(73,0 \%)$ & $-(0,0 \%)$ \\
5-SP & $1(3,2 \%)$ & $4(12,9 \%)$ & $26(83,9 \%)$ & $-(0,0 \%)$ \\
6-RJ & $2(8,0 \%)$ & $11(44,0 \%)$ & $12(48,0 \%)$ & $-(0,0 \%)$ \\
7-MG & $2(3,3 \%)$ & $26(43,3 \%)$ & $32(53,3 \%)$ & $-(0,0 \%)$ \\
TOTAL & $8(3,3 \%)$ & $73(30,4 \%)$ & $158(65,8 \%)$ & $1(0,4 \%)$ \\
\hline
\end{tabular}


Quanto ao fato dos acadêmicos terem ou não buscado formação complementar e extra acadêmica para o aprofundamento de seus conhecimentos acerca da Libras, 38 (15,8\%) responderam positivamente e 199 (82,9\%) negativamente e 3 $(1,2 \%)$ não responderam a questão.

Pode-se verificar que 148 acadêmicos (61,7\%) já se depararam com alguma situação em que necessitaram usar seus conhecimentos em Libras para estabelecer comunicação com uma pessoa surda, e 92 (38,3\%) nunca vivenciaram tal situação. A partir do Teste de Diferença de Proporções, ao nível de significância de 0,05, pode-se verificar que a proporção de discentes que já se depararam com a situação de necessidade de conhecimento de Libras é significantemente superior à proporção dos que não se deparam com tal situação $(p=0,0000)$.

Dentre os 148 acadêmicos que já utilizaram os conhecimentos adquiridos na disciplina para se comunicar com um surdo pode-se observar o predomínio de posições que consideram desfavorável seu desempenho, conforme pode ser observado na tabela 3 .

Tabela 3 - Avaliação dos acadêmicos quanto ao desempenho na comunicação com sujeitos surdos

\begin{tabular}{cccc}
\hline \multirow{2}{*}{ Instituição } & \multicolumn{2}{c}{ SIM } & NÃO \\
\cline { 2 - 3 } & Favorável & Desfavorável & $4(17,4 \%)$ \\
1-PR & $9(39,1 \%)$ & $10(43,5 \%)$ & $10(47,6 \%)$ \\
$2-P R$ & $6(28,6 \%)$ & $5(23,8 \%)$ & $11(25,6 \%)$ \\
$3-S C$ & $14(32,6 \%)$ & $18(41,8 \%)$ & $4(9,30 \%)$ \\
$4-S P$ & $16(43,2 \%)$ & $17(39,5 \%)$ & $24(77,4 \%)$ \\
$5-S P$ & $-(0,00 \%)$ & $7(22,6 \%)$ & $18(72,0 \%)$ \\
$6-R J$ & $5(20,0 \%)$ & $2(8,0 \%)$ & $21(35,0 \%)$ \\
7-MG & $12(20,0 \%)$ & $27(45,0 \%)$ & $92(38,3 \%)$ \\
TOTAL & $62(25,8 \%)$ & $86(35,8 \%)$ & \\
\hline
\end{tabular}

Dentre os 38 alunos que realizaram formação extra curricular em língua de sinais, 18 (47,3\%) afirmaram terem estabelecido contato favorável com surdos e 20 (52,6\%) desfavorável
Na tabela 4 pode-se observar a relação entre carga horária ofertada para disciplina e o desempenho com os surdos.

Tabela 4 - Relação entre a carga horária ofertada na disciplina de Libras e a avaliação dos acadêmicos quanto ao desempenho na comunicação com sujeitos surdos

\begin{tabular}{cccc}
\hline \multirow{2}{*}{ Instituição } & \multirow{2}{*}{ Carga horária } & \multicolumn{2}{c}{ AVALIAÇÃO } \\
\cline { 3 - 4 } & & Satisfatória & Insatisfatória \\
\hline 1-PR & 108 & $9(39,1 \%)$ & $14(60,9 \%)$ \\
$2-P R$ & 72 & $6(28,6 \%)$ & $15(71,4 \%)$ \\
3-SC & 30 & $14(32,6 \%)$ & $29(67,4 \%)$ \\
4-SP & 36 & $16(43,2 \%)$ & $21(56,8 \%)$ \\
5-SP & 30 & $-(0,0 \%)$ & $31(100 \%)$ \\
6-RJ & 30 & $5(20,0 \%)$ & $20(80,0 \%)$ \\
7-MG & 120 & $12(20,0 \%)$ & $48(80,0 \%)$ \\
TOTAL & - & $62(25,8 \%)$ & $178(74,2 \%)$ \\
\hline
\end{tabular}




\section{DISCUSSÃO}

As respostas dos discentes permitem verificar que se, por um lado, há um consenso em relação à natureza teórico-prática a partir da qual essa disciplina deve ser estruturada, por outro, a carga horária da disciplina de Libras variou de 30 a 120 horas. Quanto às significantes diferenças, evidenciadas nesses achados, vale ressaltar que se o Decreto $n^{\circ} 5.626 / 05$ definiu um tempo para a efetivação da inclusão da disciplina de Libras nos cursos elencados, ou seja, entre os anos de 2005 a 2015, o mesmo, assim como a Lei n¹0.436 não regulamentam aspectos referentes à carga horária e à natureza dessa disciplina ${ }^{16}$.

A falta de referenciais acerca de tais aspectos, além de implicarem numa formação distinta entre os acadêmicos de fonoaudiologia, resulta na indefinição de critérios mínimos a serem seguidos para garantir o acesso aos acadêmicos aos conhecimentos teórico-práticos fundamentais para uma formação de qualidade acerca da Libras.

Evidenciando tal situação, pode-se constatar que as Diretrizes Curriculares da Fonoaudiologia, resolução CNE/CES n5, de 19 de Fevereiro de $2002^{24}$, também não fazem menção diretamente a fundamentos, critérios e princípios necessários para orientar, nacionalmente, a estruturação e a inclusão da disciplina de Libras em seus cursos de graduação.

De qualquer forma, há de se questionar até que ponto as cargas horárias de 30, 36, 72, 108, 120 horas, ofertadas nos cursos investigados em no presente estudo, são suficientes para que os acadêmicos possam operar com uma língua que possui uma estrutura linguística diferente da língua portuguesa $^{25}$. A necessidade e a pertinência de tal questionamento são reforçadas, uma vez contemplados os achados desse estudo referentes à visão dos acadêmicos acerca da carga horária destinada a disciplina de LIBRAS, percebeu-se que um número restrito de acadêmicos a considera suficiente.

Cabe esclarecer que a inclusão da disciplina de Libras no curso de Fonoaudiologia objetiva formar profissionais aptos a estabelecer relações com surdos a partir da língua de sinais. Portanto, tal inclusão não prevê a formação de intérpretes, já que para este fim existem cursos específicos.

Ainda acerca dos aspectos estruturais da disciplina de LIBRAS, ofertada nos cursos que fizeram parte dessa pesquisa, cabe considerar que em todas as instituições a disciplina tem uma natureza teórico-prática e, portanto, a carga horária destinada a mesma deverá ser dividida de forma a contemplar essas duas dimensões da formação em Libras. Considerando que a média da carga horária é de 60,8 horas e a falta de referenciais próprios à Fonoaudiologia para a definição de carga horária mínima que a disciplina de Libras deve ser ministrada, pode-se recorrer aos cursos de formação oferecidos pela Feneis como parâmetro de análise (Federação Nacional de Educação e Integração de Surdos $)^{26}$.

Nesse sentido, destaca-se a oferta de um curso básico, dividido em 6 módulos de 20hs cada, de um curso intermediário com um módulo de $30 \mathrm{hs}$ e de um curso avançado com um módulo de 30hs, totalizando $180 \mathrm{hs}$. Tais parâmetros permitem apontar para a necessidade de revisão e de ampliação da carga horária destinada a referida disciplina nos cursos de graduação em Fonoaudiologia.

A necessidade de tal revisão é reforçada tendo em vista os achados da pesquisa que apontam que a formação complementar extra curricular não teve um impacto expressivo no desempenho dos acadêmicos na comunicação com sujeitos surdos. Além disso, a maior parte dos alunos que já se deparou com alguma situação em que precisou usar a língua de sinais considera seu desempenho insuficiente.

Outro achado importante é que apesar da carga horária da disciplina ser apontada como insuficiente, ainda assim, pode-se constatar a predominância de uma visão positiva dos acadêmicos em relação à inserção da disciplina de Libras no curso de Fonoaudiologia.

\section{CONCLUSÃO}

A partir de tal estudo pode-se evidenciar a necessidade do aprofundamento de discussões no contexto fonoaudiológico acerca da formação acadêmica voltada a Libras, bem como a definição de critérios e parâmetros que garantam um ensino de qualidade em torno de tal conteúdo.

Os achados demonstram que se por um lado dentre os acadêmicos predomina a visão de que a carga horária destinada à referida disciplina é insuficiente, por outro existe uma conscientização por parte dos mesmos quanto à importância e à necessidade da formação em Libras.

Esse estudo aponta para a necessidade do implemento de pesquisas que ofereçam elementos para o avanço na formação acadêmica fonoaudiológica voltada ao referido conteúdo, bem como, contribuam para a avanço de práticas fonoaudiológicas bilíngues, clínicas e educacionais, dirigidas a sujeitos surdos. 


\section{ABSTRACT}

Purpose: to analyze the insertion of a sign language discipline in national speech language therapy courses, approaching the number of hours spent with the discipline, the period when its offered, the structure nature, and the students evaluation about this discipline's contribution for their academic formation. Method: a questionnaire was applied to 240 speech language therapy students from seven national speech therapy graduation courses. For that, the insertion criterion adopted was that the students should have already concluded the discipline. The questionnaire was answered, in writing, inside their facilities. The results were quantitative and will be submitted in tables with absolute frequencies. Results: the results show that the students believe that the number of hours spent with the discipline is insufficient; in addition, they are aware about the importance and the need of the sign language discipline. Conclusion: this study demonstrates that the discussion about sign language in speech language therapy courses must be broader. The definition of criteria and parameters must also be discussed in order assure learning quality in those contents. The study also shows the need for more research that offers allowance to the advance in the speech language therapy graduation courses in those contents and that also contributes to an advance in bilingual speech therapy clinical, educational and practical needs directed towards the deaf individuals.

KEYWORDS: Speech, Language and Hearing Sciences; Deafness; Language; Laws; Education

\section{REFERÊNCIAS}

1. Dizeu LCT, Caporali SA. A língua de sinais constituindo o surdo como sujeito. Educ Soc. 2005; 26(91):583-97.

2. Lacerda CBF. A inclusão escolar de alunos surdos: o que dizem alunos, professores e intérpretes sobre essa experiência. Cad. Cedes. 2006; 26(69): 163-84.

3. Marin CR, Góes, MCR. A experiência de pessoas surdas em esferas de atividade do cotidiano. Cad. Cedes. 2006; 26(69): 231-49.

4. Quadros, RM. Políticas linguíscticas e educação de surdos em Santa Catarina: Espaço de negociações. Cad Cedes. 2006; 26(69): 141-61.

5. Stumpf M. Bilinguismo - relato de experiência. ETD. 2006; 7(2):285-94.

6. Gesueli ZM. Lingua(gem) e identidade: a surdez em questão. Educ Soc. 2006; 27(94): 277-92.

7. Lodi ACB, Almeida EB. Gêneros discursivos da esfera acadêmica e práticas de tradução. Interpretação Libras- Português reflexões. Tradução e comunicação, Rev Bras Trad. 2010; 20: 89-103.

8. Araújo CCM, Lacerda CBF. Esferas de atividade simbólica e a construção de conhecimento pela criança surda. Rev Bras Ed Esp. 2008; 14 (3): 427-46.

9. Quadros RM. Educação de surdos: a aquisição da linguagem. Porto Alegre: Artes Médicas, 1997.

10. Quadros RM. Efeitos de modalidade de língua: as línguas de sinais. ETD. 2006; 7(2):168-78.
11. Quadros RM. Aquisição de L1 e L2: o contexto da pessoa surda. In: Anais do Seminário: Desafios e Possibilidades na Educação Bilíngue para surdos. Rio de Janeiro: INES; 1997.p.70-87.

12. Souza RM. O professor intérprete de língua de sinais em sala de aula: ponto de partida para se repensar a relação ensino, sujeito e linguagem. ETD. 2007; 8:154-70.

13. Cruz JIG, Dias TRS. Trajetória escolar do surdo no ensino superior: condições e possibilidades. Rev Bras Ed Esp. 2009; 15(1): 65-80.

14. Brasil. Diretrizes Nacionais para Educação Especial na Educação Básica. Resolução CNE/ CEB nํ2, de 11 de Setembro de 2001.

15. Guarinello AC, Massi, G, Berberian, AP. Surdez e Linguagem Escrita: Um Estudo de Caso. Rev. Bras. Ed. Esp., Marília, Mai-Ago. 2007, 13(2): 205-18.

16. Brasil. Lei no 10.436, de 24 de abril de 2002. Língua Brasileira de Sinais - LIBRAS. Brasília, 2002.

17. Schemberg S. Educação escolar e letramento de surdos: reflexões a partir da visão de pais e professores. Rev Soc Bras Fonoaudiol. 2009; 14(3): 437.

18. Silva $A B$, Pereira MCC. A imagem que professoras da escola regular têm em relação à aprendizagem do aluno surdo. Estud. Psicol. 2003; 20(2): 5-13.

19. Lodi AC, Moura MC. Primeira língua e constituição do sujeito: uma transformação social. ETD. 2006; 7(2):1-13. 
20. Brasil. Parâmetros Curriculares Nacionais: Introdução aos Parâmetros Curriculares Nacionais / Secretaria de Educação Fundamental - Brasília: MEC/SEF, 1997.

21. Brasil. Decreto $n^{\circ} 5.626$ de 22 de Dezembro de 2005. Brasília, 2005. Língua Brasileira de Sinais LIBRAS. Brasília, 2005.

22. Silva DN. Surdez e inclusão social: o que as brincadeiras infantis têm a nos dizer sobre esse debate? .Cad. Cedes. 2006; 26 (69):121-39.

23. Franco M. Educação superior bilíngue para surdos: o sentido da política inclusiva como espaço da liberdade: primeiras aproximações. Rev Bras Ed Esp. 2009; 15(1): 15-30.
24. Brasil. Conselho Nacional de Educação. Câmara de Educação Superior. Resolução CNE/CES no5, de 19 de Fevereiro de 2002.

25. Quadros RM.Aspectos da sintaxe da aquisição da Língua Brasileira de Sinais. Letras Hoje. 1997; 110: 125-46.

26. FENEIS-PR [homepage na Internet]. Paraná: Federação Nacional de Educação e Integração de Surdos. [atualizada em 07 de setembro de 2011; acesso em 06 de setembro de 2011]. Disponível em: http://feneispr.webnode.com.br/ products/curso-de-libras/

Endereço para correspondência:

Ana Cristina Guarinello Rua Alexandre Eduardo Klat, 66/02

Abranches - Curitiba - PR

CEP: 82130-120

E-mail: ana.guarinello@utp.br 